Supported by the March of Dimes Birth Defects Foundation and by Public Health Service grants P01ES-05622 and P30ES-02109 from the National Institute of Environmental Health Sciences, National Institutes of Heaith, Department of Health and Human Services.

We thank the nurses and residents of the Medical Center of Central MassachusettsMemorial for their assistance. We especially thank the women who cooperated in this study.

Manuscript received September 9, 1992; revised November 25, 1992; accepted December 2, 1992.

\section{Restoration of Taxol Sensitivity of Multidrug- Resistant Cells by the Cyclosporine SDZ PSC 833 and the Cyclopeptolide SDZ 280-446}

\author{
Bénédicte Jachez, Rene \\ Nordmann, Francis Loor*
}

Background: Taxol, a promising agent for the treatment of cancer, has entered phase II clinical trials. Nevertheless, it belongs to the class of compounds that show impaired retention in multidrug-resistant cells expressing P-glycoprotein (Pgp), a drug efflux pump. Chemosensitizers like verapamil modulate multidrug resistance by interfering with the efflux action of Pgp and thus can decrease drug resistance or can restore drug sensitivity by restoring normal drug accumulation and distribution within the multidrugresistant tumor cell. The two strongest, nearly equipotent chemosensitizers identified to date are the cyclosporine derivative SDZ PSC 833 and the semisynthetic cyclopeptolide SDZ 280-446. Purpose: This study was designed to investigate the capacities of verapamil, SDZ PSC 833, and $S D Z 280-446$ to decrease resistance of two multidrug-resistant cell lines to taxol. Methods: We studied in vitro the growth of two multidrugresistant tumor cell lines displaying high resistance to taxol: multidrugresistant Chinese hamster ovary cells and murine monocytic leukemia P388 cells. We determined the taxol concentration that produced $50 \%$ inhibition of cell growth $\left(\mathrm{IC}_{50}\right)$ in the two multidrug-resistant cell lines and in the parent cell lines, in the presence of a range of chemosensitizer concentrations $(0-30 \mu M)$. IC IC $_{50}$ values were determined in the presence and in the absence of verapamil, SDZ PSC 833, or SDZ 280-446. Results: At nontoxic concentrations $\mathbf{( 0 . 3 - 1}$ $\mu M)$, SDZ PSC 833 and SDZ 280-446 produced an almost complete reversal of the high taxol resistance of the multidrug-resistant tumor cells, whereas only partial restoration of sensitivity to taxol was achieved with verapamil. Conclusion: SDZ PSC 833 and SDZ 280-446 can restore the normal taxol sensitivity of highly resistant multidrug-resistant tumor cells. Implications: The combination of taxol with SDZ PSC 833 or SDZ 280-446 may be recommended for treatment of multidrug-resistant cancers. [J Natl Cancer Inst 85:478-483, 1993]

Taxol (NSC-125973) is a new anticancer agent $(1,2)$ presently undergoing phase I and II clinical trials $(3,4)$. This drug is isolated from trees of the genus Taxus, and its ability to arrest cell proliferation in the $G_{2}$ and $M$ phases of the cell cycle is well documented $(5,6)$. This capacity correlates with its unusual properties of interaction with tubulin in vitro (hyperstabilization of microtubules) (I).

Unfortunately, a major mechanism of cellular resistance to taxol is the increased drug efflux out of cells that display the "classic" multidrugresistant phenotype. An increased capacity to pump out a variety of drugs with unrelated structures and intracellular targets (e.g., vinca alkaloids, doxorubicin, etoposide, dactinomycin, and colchicine) correlates with increased levels of mdr gene-encoded membrane glycoproteins (P-glycoprotein) $(7,8)$.

A variety of agents can decrease in vitro the drug resistance of multidrugresistant tumor cells and sometimes completely restore their sensitivity to chemotherapeutic agents. Such chemo- sensitizers belong to various structural classes. By interfering with the efflux function of P-glycoprotein (Pgp), they can decrease drug resistance or can restore drug sensitivity by restoring the normal drug accumulation and distribution within the multidrug-resistant tumor cell $(7,8)$. Among these chemosensitizers, the calcium channel blocker verapamil (7) has been the most commonly studied. Nevertheless, very potent chemosensitizers have been most commonly identified among cyclosporines $(9,10)$ and cyclopeptolides (II) derived from a Fungi imperfecti (Septoria sp.). Extensive studies of chemically modified derivatives of cyclosporines and cyclopeptolides led to the selection of the two strongest, nearly equipotent chemosensitizers identified to date: the cyclosporine derivative SDZ PSC 833 and the semisynthetic cyclopeptolide SDZ 280-446 $(11,12)$.

How taxol is processed by $\mathrm{Pgp}$ is unknown, and whether SDZ PSC 833 and SDZ 280-446 could restore a normal sensitivity to taxol was not predictable. The present study was, thus, aimed at $(a)$ measuring the level of taxol resistance displayed by two multidrug-resistant tumor cell lines extensively studied in our laboratory and (b) testing whether taxol resistance could be modulated by verapamil, SDZ PSC 833, and SDZ 280-446.

\section{Materials and Methods}

\section{Cell Lines}

Parental and multidrug-resistant Chinese hamster ovary (CHO) cells (13) were obtained from Dr. V. Ling (Ontario Cancer Institute, Toronto, Canada). Parental and multidrug-resistant murine monocytic leukemia P388 cells (14) were obtained from Dr. M. Grandi (Farmitalia Carlo Erba Research Center, Milan, Italy). The multidrug-resistant $\mathrm{P388}$ cell line has been selected by growth in the presence of doxorubicin for the multidrug-resistant phenotype (14). The multidrug-resistant $\mathrm{CHO}$ cell line has been selected by growth in the presence of colchicine for the multidrug-resistant phenotype (13). Detailed information on the properties of these cell lines (i.e., sensitivity to various drugs and effects of various chemosensitizers) has been published by our laboratory (9-12).

"See "Notes" section following "References." 
The parental $\mathrm{CHO}$ cell line AuxB $_{1}$ subclone $\mathrm{ABISII)}$ and the multidrug-resistant $\mathrm{CHO}$ line $\left(\mathrm{CH}^{\mathrm{R} C 5}\right.$ subclone $\mathrm{C5S3.2}$ ) (13) have been extensively studied with regard to the capacity of various cyclosporines (9) and other chemosensitizers (10) to reverse the multidrug-resistant phenotype in vitro. These studies led to the development of the novel cyclosporine derivative SDZ PSC 833 and the novel semisynthetic cyclopeptolide SDZ 280-446 $(11,12)$.

The parental P388 line (P388N) and the multidrug-resistant P388 line (P388-Dox ${ }^{\mathrm{R}}$ ) (14) have been used to compare in vitro the resistance-modulating activity of FK-506 and cyclosporin A (15), to evaluate the restoration of daunomycin retention in vitro by a variety of chemosensitizers (16), and to select the SDZ PSC $833(12,17)$ and SDZ 280-446 (11) development compounds.

\section{Anticancer Drugs and Chemosensitizers}

For preliminary experiments aimed at testing the taxol resistance of our cell lines, we obtained taxol (from Taxus baccata) from the National Cancer Institute, National Institutes of Health,
Bethesda, Md. For subsequent experiments aimed at reversing the taxol resistance of our multidrugresistant cell lines, we purchased taxol (from Taxus brevifolia) from Calbiochem AG, Buchs, Switzerland. The taxol was prepared as a $10-\mathrm{mg} /$ $\mathrm{mL}$ stock solution in pure ethanol. Verapamil was purchased from Sigma Chemical Co. (St. Louis, Mo.) and prepared as a $100-\mathrm{mM}$ stock solution in pure ethanol. SDZ PSC 833 and SDZ 280-446 were synthesized by Sandoz Pharma Ltd. (Basel, Switzerland) and were prepared as $10-\mathrm{m} M$ stock solutions in ethanol.

\section{Chemosensitizer Capacity Assay}

Cell cultures were prepared as described previously (9). Briefly, the cultures were made to a final volume of $0.2 \mathrm{~mL}$ in 96-well microplates at $37^{\circ} \mathrm{C}$ in a humidified atmosphere of $7 \% \mathrm{CO}_{2}$ and $93 \%$ air. Three-day cultures of P388 cells were initiated with 2000 parental P388 cells or 5000 multidrug-resistant $\mathrm{P} 388$ cells per well. Five-day cultures of $\mathrm{CHO}$ cells were initiated with 400 parental CHO cells or 800 multidrugresistant CHO cells per well. Growth was measured by a colorimetric assay, as described previously (9).
The cell growth inhibitory effect of the chemosensitizer alone, in the presence of the taxol solvent (ethanol), was expressed as percent of the growth level obtained in the absence of both chemosensitizer and taxol, but in the presence of their solvent (ethanol) $(10,12)$.

The taxol $\mathrm{IC}_{50}$ (the concentration producing $50 \%$ inhibition of cell growth) was calculated from the dose-response curves obtained by plotting the measured growth versus the taxol concentration, as shown in Fig. 1. A whole range of $\mathrm{IC}_{50}$ values were obtained in the presence of the chemosensitizer (verapamil, SDZ PSC 833, or $\mathrm{SDZ} 280-446 \mathrm{~A}$ ) (i.e., $\mathrm{IC}_{50}{ }^{+}$); values were also obtained in the absence of chemosensitizer, but in the presence of its solvent $(10,12)$ (i.e., $\left.\mathrm{IC}_{50^{-}}\right)$. The increases of taxol sensitivity, or "gains" in sensitivity, were given by the ratio $\mathrm{IC}_{50}-/ \mathrm{IC}_{50}{ }^{+}$, and a gain was calculated for each chemosensitizer concentration $(l l)$.

\section{Results}

\section{Taxol Resistance}

The multidrug-resistant P388 cells were approximately 283 -fold more re-

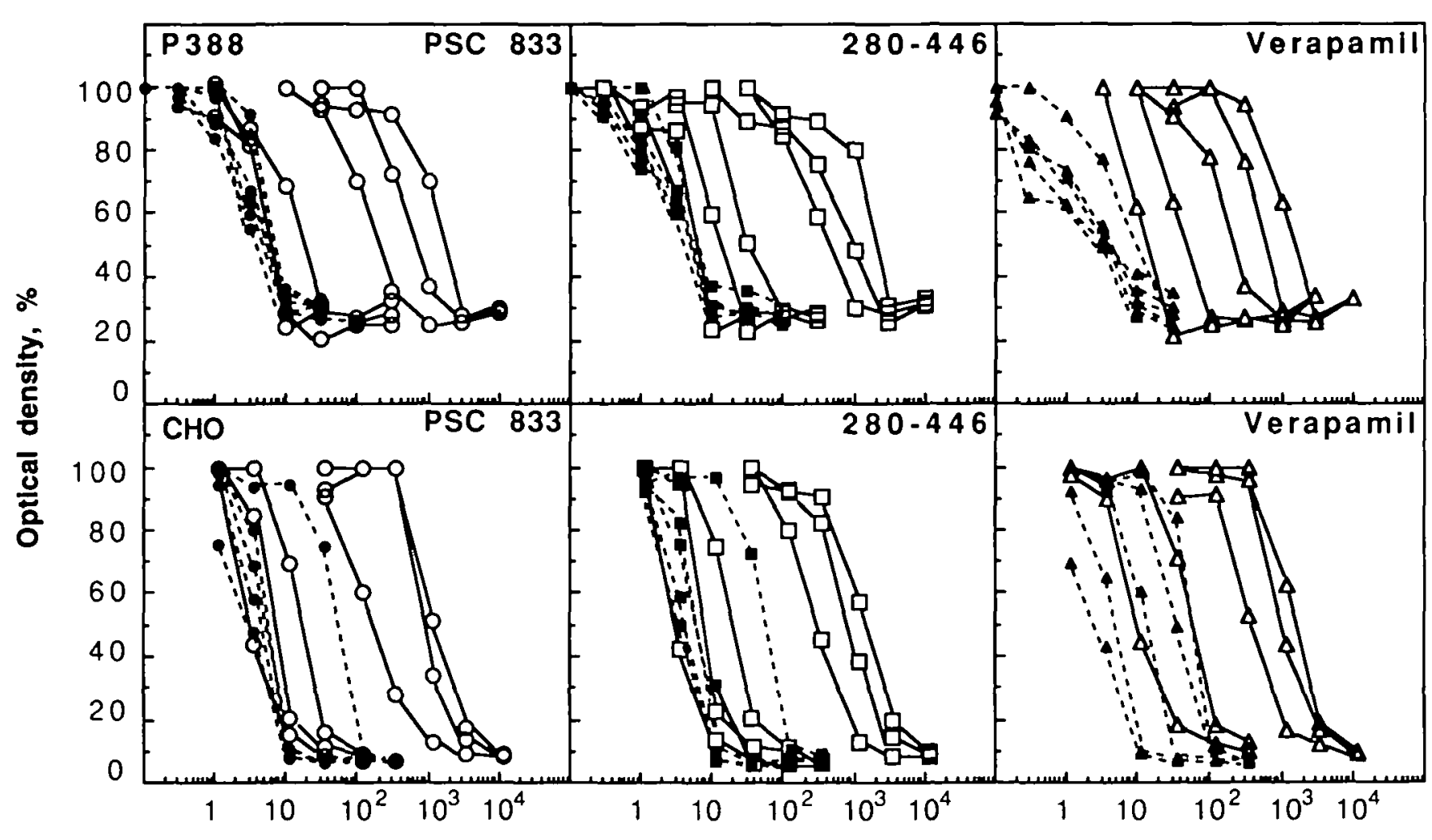

Taxol, $n M$

Fig. 1. Taxol-mediated cell growth inhibition. Results from a typical experiment showing cell growth (as percent of control growth; Y-axes) as a function of the taxol concentration (as $\mathrm{n} M$; $\mathrm{X}$-axes). Cell growth was measured by the optical density and taken as $100 \%$ in control culture wells (cells exposed to solvent only, run on each microculture plate). Dose-response curves obtained with P388 and CHO cell lines are shown, respectively, at the top and bottom of the figure (open symbols and solid lines for multidrug-resistant cells, and closed symbols and broken lines for parental cells). On each graph, curves from right to left were obtained in the presence of increasing concentrations of SDZ PSC 833 or SDZ 280-446 $(0,0.01,0.03,0.1,0.3$, and $1 \mu M)$ or of verapamil $(0,1,3,10$, and $30 \mu M)$. 
sistant to taxol than the parental P388 cells (Table 1). This increase compares with mean values of 130 -fold for colchicine, 158-fold for daunomycin, 101-fold for doxorubicin, 140-fold for etoposide, and 158-fold for vincristine (I2).

The multidrug-resistant $\mathrm{CHO}$ cells were approximately 36 -fold more resistant to taxol than the parental $\mathrm{CHO}$ cells (Table 1). This increase compares with mean values of 54-fold for colchicine, 93-fold for daunomycin, 47fold for etoposide, and 28-fold for vincristine (I2). Higher relative resistance indices (Table 1) were observed for the P388 cells than for the CHO cells. This result may be partly due to the fact that the parental P388 cells were not sensitizable by Pgp-directed chemosensitizers $(15,16)$ and did not express immunodetectable levels of Pgp (10), whereas the parental CHO cells themselves displayed a low level of innate resistance $(9,10)$; this lowlevel resistance is presumably associated with their expression of low levels of Pgp $(18,19)$.

\section{Chemosensitization of P388 Cells}

No sensitization of the parental P388 cells could be obtained by the chemosensitizers tested (verapamil, SDZ PSC 833, and SDZ 280-446). The taxol $\mathrm{IC}_{50}$

Table 1. Anticancer drug resistance of P388 and CHO cell lines

\begin{tabular}{lcc}
\hline & \multicolumn{2}{c}{ Cell line* } \\
\cline { 2 - 3 } Anticancer drug & P388 & CHO \\
\hline Colchicinet & 130 & 54 \\
Daunomycin $\dagger$ & 158 & 93 \\
Doxorubicint & 101 & ND \\
Etoposidet & 140 & 47 \\
Vincristine $\dagger$ & 158 & 28 \\
Taxol & 283 & 36 \\
Parent cell & $6.1 \pm 0.7$ & $50.8 \pm 13.6$ \\
IC & & \\
Multidrug- & $1729 \pm 272$ & $1828 \pm 26$ \\
$\quad$ resistant & & \\
cell IC & & \\
\hline
\end{tabular}

* Unless otherwise specified, numbers = relative resistance index (multidrug-resistant cell $I_{\text {so }}$ /parent cell $\left(C_{s 0}\right)$. ND = not determined.

tIndices calculated using $I_{\text {so }}$ values previously obtained and published by our group (I2).

$\ddagger$ Mean values \pm SD of 20 determinations within four individual experiments. remained in the 4-6 $n M$ range for concentrations of SDZ PSC 833 and SDZ $280-446$ of 0.01 to $1.0 \mu M$. There was also no decrease in the taxol $\mathrm{IC}_{50}$ of the parental P388 cells for verapamil concentrations up to $30 \mu \mathrm{M}$. Similarly, no major growth inhibition of the parental P388 cells was caused by the chemosensitizers alone at concentrations below $1 \mu M$ (Fig. 2). Thus, our strongest chemosensitizers (SDZ PSC 833 and SDZ 280-446), did not significantly sensitize (less than twofold increase) the parental P388 cells to taxol, as has been found with other drugs (colchicine, vincristine, daunomycin, doxorubicin, and etoposide) and with Pgp probes (rhodamine 123 and others) $(11,12,16)$.

In the case of the multidrug-resistant P388 cells, a virtually complete reversal of taxol resistance could be achieved with SDZ PSC 833 and SDZ 280-446 but not verapamil. Indeed, a taxol $\mathrm{IC}_{50}$ of about $1800 \mathrm{nM}$, as obtained in the absence of any chemosensitizer, could be reduced to about 6 $\mathrm{n} M$ in the presence of $1 \mu M$ of $\mathrm{SDZ}$
PSC 833 or SDZ 280-446 (Table 2). These chemosensitizer concentrations were not inhibitory ( $<20 \%$ inhibition) by themselves for multidrug-resistant P388 cell growth (Fig. 2). At a concentration at which it was not substantially inhibitory by itself (1 $\mu M)$, verapamil could sensitize the cells only weakly (taxol $\mathrm{IC}_{50}$ of about $700 \mathrm{nM})$; at a concentration $(30 \mu M)$ at which it slightly inhibited multidrugresistant P388 cell growth by itself (Fig. 2), verapamil still could not bring the taxol $\mathrm{IC}_{50}$ to its expected baseline of 4-6 $n M$ (Table 2). (The expected baseline was the range of $\mathrm{IC}_{50}$ values obtained with this type of assay with a panel of sensitive cell lines.)

\section{Chemosensitization of CHO Cells}

The taxol $\mathrm{IC}_{50}$ of about $50 \mathrm{n} M$ shown by the parental, absence of chemosensitizer could be reduced to the apparent baseline of 2-4 $\mathrm{n} M$ by the three chemosensitizers (Table 2). SDZ PSC 833 and SDZ 280-446 were stronger chemosensitizers

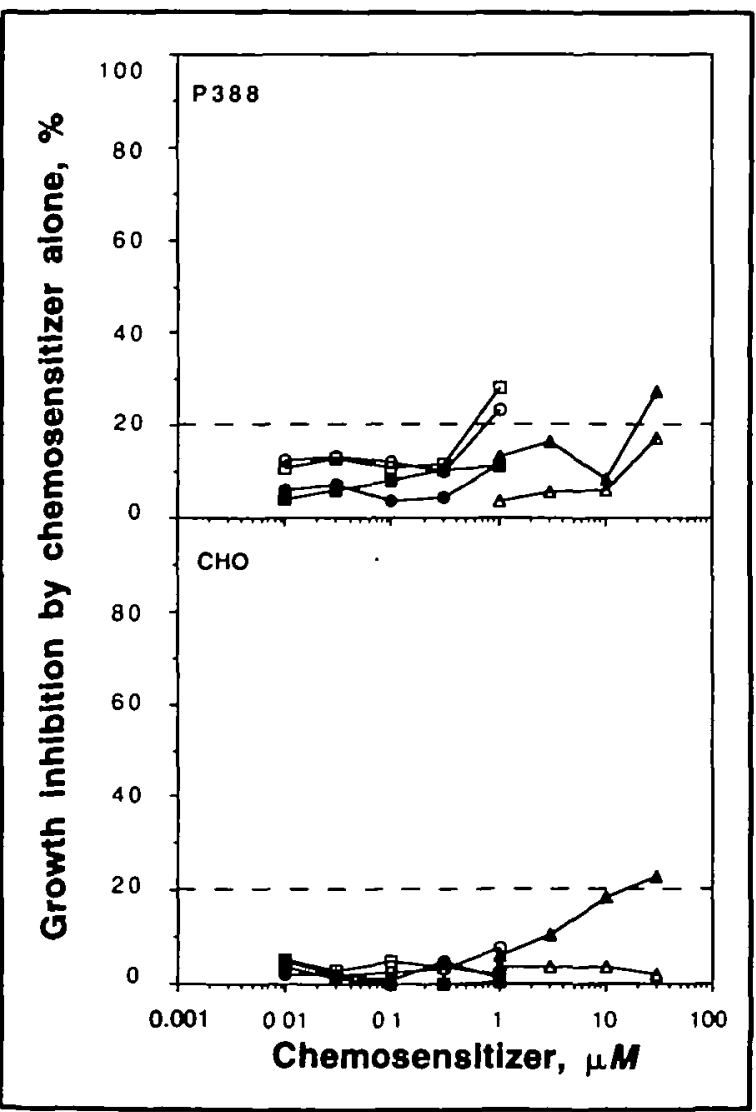

Fig. 2. Chemosensitizer-induced cell growth inhibition. Cell growth inhibition (as percent of control growth; $\mathrm{Y}$-axes) is shown as a function of chemosensitizer concentration (as $\mu M ; \quad \mathrm{X}$-axes). Growth inhibition was calculated as the difference between growth in the absence and presence of chemosensitizer. Open symbols represent parental cells, and closed symbols represent multidrugresistant cells (circles for SDZ PSC 833, squares for SDZ 280-446, and triangles for verapamil). Values are means of two to four experiments. 
Table 2. Taxol resistance-modulating activity of SDZ PSC 833, SDZ 280-446, and verapamil for P388 and CHO cell lines

\begin{tabular}{|c|c|c|c|c|c|c|}
\hline \multirow{3}{*}{$\frac{\text { Chemosensitizer }}{\text { SDZ PSC } 833}$} & \multirow{3}{*}{$\begin{array}{c}\text { Concentration, }{ }^{*} \mu M \\
0 \\
0.01\end{array}$} & \multicolumn{5}{|c|}{ Taxol $I_{S 0,} \mathrm{nM}$} \\
\hline & & \multicolumn{2}{|c|}{ P388 cells } & \multicolumn{3}{|c|}{ CHO cells } \\
\hline & & \multirow[b]{2}{*}{$\begin{array}{c}\text { Parent } \\
6.3 \pm 0.9 \\
5.5 \pm 0.2 \\
4.9 \pm 0.2 \\
5.2 \pm 1.1 \\
4.5 \pm 0.9 \\
4.5 \pm 1.8\end{array}$} & Multidrug-resistant & \multirow[b]{2}{*}{$\begin{array}{c}\text { Parent } \\
50.2 \pm 13.0 \\
5.5 \pm 0.4 \\
3.9 \pm 1.7 \\
4.0 \pm 1.5 \\
3.7 \pm 1.3 \\
3.4 \pm 1.3\end{array}$} & \multicolumn{2}{|c|}{ Multidrug-resistant } \\
\hline SDZ PSC 833 & $\begin{array}{l}0 \\
0.01 \\
0.03 \\
0.1 \\
0.3 \\
1\end{array}$ & & $\begin{aligned} 1812 & \pm 151 \\
665 & \pm 218 \\
241 & \pm 179 \\
38.5 & \pm 24 \\
10.9 & \pm 7.1 \\
6.3 & \pm 1.6\end{aligned}$ & & $\begin{array}{r}1662 \\
994 \\
195 \\
18.3 \\
7.3 \\
3.0\end{array}$ & $\begin{array}{l} \pm 344 \\
\pm 170 \\
\pm 52 \\
\pm 2.7 \\
\pm 0.9 \\
\pm 0.5\end{array}$ \\
\hline SDZ $280-446$ & $\begin{array}{l}0 \\
0.01 \\
0.03 \\
0.1 \\
0.3 \\
1\end{array}$ & $\begin{array}{l}6.0 \pm 0.8 \\
5.1 \pm 0.2 \\
4.7 \pm 0.6 \\
4.5 \pm 0.4 \\
4.7 \pm 1.1 \\
5.2 \pm 1.2\end{array}$ & $\begin{aligned} 1760 & \pm 195 \\
975 & \pm 141 \\
518 & \pm 116 \\
69 & \pm 33 \\
22.3 & \pm 8.9 \\
7.2 & \pm 1.0\end{aligned}$ & $\begin{aligned} 49.7 & \pm 14.6 \\
8.3 & \pm 0.5 \\
5.7 & \pm 0.9 \\
4.4 & \pm 1.8 \\
3.9 & \pm 1.6 \\
3.5 & \pm 1.3\end{aligned}$ & $\begin{array}{r}1886 \\
835 \\
221 \\
25.3 \\
10.8 \\
3.8\end{array}$ & $\begin{array}{l} \pm 223 \\
\pm 48 \\
\pm 115 \\
\pm 5.2 \\
\pm 3.8 \\
\pm 0.9\end{array}$ \\
\hline Verapamil & $\begin{array}{r}0 \\
1 \\
3 \\
10 \\
30\end{array}$ & $\begin{array}{l}5.9 \pm 0.7 \\
4.7 \pm 1.2 \\
3.9 \pm 1.5 \\
4.2 \pm 1.3 \\
3.7 \pm 1.6\end{array}$ & $\begin{aligned} 1613 & \pm 428 \\
742 & \pm 311 \\
246 & \pm 91 \\
60.7 & \pm 16 \\
18.5 & \pm 3.3\end{aligned}$ & $\begin{aligned} 52.4 & \pm 17 \\
31.7 & \pm 20 \\
22.3 & \pm 25 \\
4.2 & \pm 1.6 \\
2.7 & \pm 0.8\end{aligned}$ & $\begin{array}{r}1950 \\
1226 \\
352 \\
66 \\
15\end{array}$ & $\begin{array}{l} \pm 87 \\
\pm 325 \\
\pm 60 \\
\pm 7.6 \\
\pm 5.6\end{array}$ \\
\hline
\end{tabular}

* The same solvent concentration was present in all samples. Mean value of two to four experiments \pm SD.

than verapamil, inasmuch as this baseline was approached by $0.03 \mu M \mathrm{SDZ}$ PSC 833 and $0.1 \mu M$ SDZ $280-446$ but required $10 \mu M$ verapamil. The parental CHO cells were slightly resistant to the multidrug resistance-modifying agents, with higher drug $\mathrm{IC}_{50} \mathrm{~s}$ than for parental tumor cell lines of other origins (e.g., L1210 and KB-3.1), as observed earlier with several other drugs (e.g., colchicine and etoposide) and with these and other chemosensitizers (e.g., amiodarone and quinidine) (9-12). The resistance of the parental CHO cells can be abrogated by very low concentrations of strong chemosensitizers or by higher doses of weak chemosensitizers (unpublished data from the study of nearly 1000 compounds). This chemosensitizing activity can probably be explained by the inhibition of the small amounts of Pgp expressed by the parental $\mathrm{CHO}$ cells $(18,19)$. With little $\mathrm{Pgp}$ function to neutralize, the maximum gains in sensitivity were, of course, correspondingly low (<20-fold) (9-12).

The multidrug-resistant $\mathrm{CHO}$ cells were highly resistant to taxol, with an $\mathrm{IC}_{50}$ of about $1800 \mathrm{nM}$, but were completely sensitizable by $1 \mu M \mathrm{SDZ}$ PSC 833 or SDZ 280-446 (Table 2). Those chemosensitizer concentrations gave no detectable inhibition of multidrug-resistant $\mathrm{CHO}$ cell growth (Fig. 2). Moreover, even $30 \mu M$ verapamil could not bring the taxol $\mathrm{IC}_{50}$ to the apparent 2-4 $\mathrm{n} M$ baseline, although it produced a taxol $\mathrm{IC}_{50}$ of about $2.7 \mathrm{n} M$ in untreated parental CHO cells.

\section{Discussion}

Taxol is a promising anticancer drug $(20,21)$, as shown by recent clinical studies $(2-4)$, but it belongs to the class of compounds that can be effluxed by multidrug-resistant cells expressing Pgp (l). Fortunately, as shown in Table 2 and Fig. 2, taxol resistance can be virtually neutralized by nontoxic concentrations (0.3-1 $\mu M)$ of SDZ PSC 833 or SDZ $280-446$.

In the present study, gains in taxol sensitivity of 250 - to 300 -fold could be reached with the multidrug-resistant P388 cells. (For calculation of gains, see the "Materials and Methods" section.) In equimolar comparisons, SDZ PSC 833 seemed to be slightly more active than SDZ $280-446$ for the reversal of taxol resistance, but the difference was small (about twofold). Much higher concentrations of verapamil were required to obtain comparable gains.

With the multidrug-resistant $\mathrm{CHO}$ cells, gains of about ninefold and about 550-fold could be obtained by $0.03 \mu M$ and $1 \mu M$, respectively, of either SDZ PSC 833 or SDZ 280-446. These chemosensitizers appeared to be equipotent for chemosensitizing this cell line and much stronger than verapamil: A maximum gain of sensitization of 130 -fold required $30 \mu M$ verapamil.

The two multidrug-resistant tumor cell lines in the present study displayed a level of taxol resistance similar to their levels of resistance shown for several other drugs of unrelated structure and mode of action (Table 1). In contrast, a taxol-resistant J774.2 cell subline, obtained by growing the cells with taxol (22), displayed a much higher resistance to taxol (833-fold), and showed clearly weaker crossresistance to colchicine (58-fold), vinblastine (43-fold), puromycin (97-fold), doxorubicin (128-fold), and dactinomycin (88-fold). These cells exhibited a decreased accumulation of taxol in comparison with sensitive cells, which could be correlated with the presence of a 135-kd phosphoprotein (22).

The multidrug-resistant phenotype of tumor cells, even when mediated only by Pgp overexpression (i.e., with no other known resistance mechanism), does not display constant features: Each Pgp-expressing multidrugresistant cell line can display its own pattern of cross-resistance $(7,8)$. Therefore, it could be expected that a given multidrug-resistant cell line may also show different degrees of chemosensi- 
tization by different chemosensitizers for different drugs.

Distinct drug binding-transport sites on the Pgp might indeed exist for different drugs or groups of drugs. Colchicine does not inhibit the in vitro photolabeling of Pgp by a vinblastine analog, whereas vinca alkaloids, verapamil, and diltiazem were able to do so $(23,24)$. Both calcium channel blockers, verapamil and diltiazem, were also able to inhibit Pgp photolabeling by a cyclosporine analog, whereas colchicine in similar concentrations had no effect (25). Thus, the colchicine binding-transport site on Pgp might be distinct from the vinca alkaloid site.

In a recent study, the two most commonly used chemosensitizers, verapamil and quinidine, could not restore the retention of rhodamine 123 in the same multidrug-resistant P388 cell line as that used in the present study (26), although they could restore daunomycin retention (16); in contrast, amiodarone, cyclosporin A, SDZ 280-446, and SDZ PSC 833 could restore the retention of both Pgp-function probes $(16,26)$. These results show that different chemosensitizers may differently affect drug transport by $\mathrm{Pgp}$ molecules.

Besides this variable efficacy of chemosensitizers mediated by the wildtype Pgp of multidrug-resistant cells, an additional variability in the gains of sensitivity may depend on Pgp polymorphism resulting from somatic mutations in response to selective pressure. Typically, a series of multidrug-resistant $\mathrm{KB}$ epidermoid carcinoma (ATCC CCL17) cell lines, which had been obtained by independent selection with colchicine, vinblastine, or doxorubicin, displayed a definitely preferential relative resistance to the drug used for selection, although they displayed a broad cross-resistance to the other drugs (8). Single point mutations sufficient to dramatically affect the profile of resistance conferred by the wild-type Pgp, such as a marked alteration of the relative resistance to colchicine, vinblastine, and doxorubicin, were caused by a single glycine-valine interchange (27). Similarly, mutations in the hamster pgpl gene conferred a distinctive multidrug-resistant profile to dactinomycin-selected sublines of multidrug-resistant DC/3F cells: Highest resistance was now for dactinomycin in- stead of colchicine as in the parental line (28). Thus, while one mutation increased colchicine resistance in one instance (27), a different mutation decreased it in the other (28). Finally, multidrug-resistant $\mathrm{J774.2}$ sublines selected by growth in the presence of colchicine, vinblastine, or taxol developed heterogeneous forms of multidrug resistance-associated glycoproteins (29-3I). Such glycoproteins of the taxolresistant sublines were found to be similar but not identical to the classic Pgp expressed in vinblastine- and colchicine-resistant sublines derived from the same parent $(29,30)$.

Eventually, the taxol-specific molecular variants $(24,25)$ of the multidrug resistance-associated glycoproteins might display altered chemosensitization profiles in comparison with the bona fide mdrl-encoded Pgp, although the taxol resistance of resistant $\mathrm{CHO}$ cells could be reversed by verapamil (32). In this respect, it would thus be interesting to study how active SDZ PSC 833 and SDZ 280-446 are with such taxolinduced variants of multidrug resistanceassociated glycoproteins.

In conclusion, precisely how taxol is processed by Pgp molecules remains unknown. Nonetheless, tumor cell resistance to taxol can be abrogated by either the cyclosporine SDZ PSC 833 or the cyclopeptolide SDZ 280-446. The combination of taxol with either SDZ PSC 833 or SDZ $280-446$ may be recommended for the treatment of multidrugresistant cancers.

\section{References}

(1) Bender RA, Hamel E, Hande KR: Plant alkaloids. In Cancer Chemotherapy: Principles and Practice (Chabner BA, Collins JM, eds). Philadelphia: Lippincott, 1990, Pp 253-274

(2) Rowinsky EK, DONenower RC: Taxol: Twenty years later, the story unfolds. J Natl Cancer Inst 83:1778-1781, 1991

(3) Wiernik PH, Schwartz El, Strauman JJ, ET AL: Phase I clinical trial and pharmacokinetic study of taxol. Cancer Res 47:2486-2493, 1987

(4) Holmes FA, Walters RS, Theriault TL, ET AL: Phase II trial of taxol, an active drug in the treatment of metastatic breast cancer. J Natl Cancer Inst 83:1797-1805, 1991

(5) Schiff PB, Horwitz SB: Taxol stabilizes microtubules in mouse fibroblast cells. Proc Natl Acad Sci U S A 77:1561-1565, 1980

(6) Koponen M, Grieder A, Loor F: The effects of cyclosporins on the cell cycle of t-lymphoid cell lines. Exp Cell Res 140:237-250, 1982
(7) Georges E, Sharom FJ, Lino V: Multidrug resistance and chemosensitization: Therapeutic implications for cancer chemotherapy. Adv Pharmacol 21:185-220, 1990

(8) Pastan IH, Gottesman MM: Molecular biology of multidrug resistance in human cells. Important Adv Oncol 1:3-16, 1988

(9) Gavériaux C, Boesch D, Boelsterli JJ, ET AL: Overcoming multidrug resistance in Chinese hamster ovary cells in vitro by cyclosporin A (Sandimmune) and nonimmunosuppressive derivatives. $\mathrm{Br} \mathrm{J}$ Cancer 60:867-871, 1989

(10) Boesch D, Gavériaux C, Loor F: Reversal of multidrug-resistance in $\mathrm{CHO}$ cells by cyclosporin $A$ and other resistance modifying agents. J Cell Pharmacol 2:92-98, 1991

(II) LoOr F, Boesch D, Gavériaux C, et al: SDZ 280-446, a novel semi-synthetic cyclopeptolide: In vitro and in vivo circumvention of the P-glycoprotein-mediated tumour cell multidrug resistance. $\mathrm{Br} \mathrm{J}$ Cancer 65:11-18, 1992

(I2) Gaveriaux C, Boesch D, Jachez B, et AL: SDZ PSC 833, a non-1mmunosuppressive cyclosporin analog, is a very potent multidrug-resistance modifier. J Cell Pharmacol 2:225-234, 1991

(13) Kartner N, Riordan JR, Lino V: Cell surface P-glycoprotein associated with multidrug resistance in mammalian cell lines. Science 221:1285-1288, 1983

(14) Grandi M, Youno C, Bellini O, et al: Pleiotropic multidrug resistant LoVo, P388 and 1-407 cell lines have an increased tubulovesicular compartment. Proc AACR 28:279, 1987

(15) Pourtier-Manzanedo A, Boesch D, LoOR F: FK-506 (fujimycin) reverses the multidrug resistance of tumor cells in vitro. Anticancer Drugs 2:279-283, 1991

(16) Boesch D, Muller K, PourtierMANZANEDo A, ET al: Restoration of daunomycin retention in multidrug-resistant P388 cells by submicromolar concentrations of SDZ PSC 833, a nonimmunosuppressive cyclosporin derivative. Exp Cell Res 196:26-32, 1991

(I7) Boesch D, Gaveriaux C, Jachez B, et AL: In vivo circumvention of P-glycoprotein-mediated multidrug resistance of tumor cells with SDZ PSC 833. Cancer Res $51: 4226-4233,1991$

(18) Van der Bliek AM, Van der VejdeKoERST T, LING V, ET AL: Overexpression and amplification of five genes in a multidrug-resistant Chinese hamster ovary cell line. Mol Cell Biol 6:1671-1678, 1986

(19) SCheper RJ, Bulte JW, Brakkee JG, et AL: Monoclonal antibody JSB-1 detects a highly conserved epitope on the P-glycoprotein associated with multi-drug-resistance. Int J Cancer 42:389-394, 1988

(20) Wan MC, Taylor HL, Wall ME, et al: Plant antitumor agents. VI. The isolation and structure of taxol, a novel antileukemic and antitumor agent from Taxus brevifolia. J Am Chem Soc 93:2325-2327, 1971

(2l) Fuchs DA, Johnson RK: Cytologic evidence that taxol, an antineoplastic agent from Taxus brevifolia, acts as a mitotic spindle poison. Cancer Treat Rep 62:12191222, 1978

(22) Roy SN, Horwtrz SB: A phosphoglycoprotein associated with taxol resistance in J774.2 cells. Cancer Res 45:3856-3863, 1985

(23) Cornwell MM, Safa AR, Felsted R, et AL: Membrane vesicles from multidrug- 
resistant human cancer cells contain a specific 150 to $170-\mathrm{kDa}$ protein detected by photoaffinity labeling. Proc Natl Acad Sci U S A 83:3847-3850, 1986

(24) TAMAI I, SAFA AR: Competitive interaction of cyclosporins with the vinca alkaloidbinding site of P-glycoprotein in multidrugresistant cells. J Biol Chem 265:1650916513, 1990

(25) Foxwel 1 BM, Mackie A, Lino V, et al: Identification of the multiple resistancerelated P-glycoprotein as a cyclosporine binding protein. Mol Pharmacol 36:543 546, 1989

(26) Pourtter-Manzanedo A, Didier AD, MUller CD, ET AL: SDZ PSC 833 and SDZ 280-446 are the most active of various resistance-modifying agents in restoring the rhodamine-123 retention within multidrug resistant (MDR) P388 cells. Anticancer Drugs 3:419-425, 1992

(27) Choi K, Chen CI, Krieger M, et al: An altered pattern of cross-resistance in multidrug-resistant human cells results from spontancous mutations in the mdrl ( $P$ glycoprotein) gene. Cell 53:519-529, 1988

(28) Devine SE, Lino V, Melera PW: Amino acid substitutions in $\mathrm{P}$-glycoprotein alter multidrug resistance. Proc Natl Acad Sci U S A 89:4564-4568, 1992

(29) Zeheb R, BeTtTenmilleR HF, HoRwtiz SB: Use of antibodies to probe membrane glycoproteins associated with drug-resistant J774.2 cells. Biochem Biophys Res Commun 143:732-739, 1987

(30) Greenberoer LM, WILlams SS, HoRwTrZ SB: Biosynthesis of heterogeneous forms of multidrug resistanceassociated glycoproteins. J Biol Chem 262:13685-13689, 1987

(3I) GreENBERGER LM, LOTHSTEIN L, Williams SS, ET AL: Distinct P-glycoprotein precursors are overproduced in independently isolated drug-resistant cell lines. Proc Natl Acad Sci U S A 85:3762-3766 1988

(32) RACker E, Wu LT, WescotT D: Use of slow $\mathrm{Ca}^{+}$channel blockers to enhance inhibition by taxol of growth of drug sensitive and -resistant Chinese hamste ovary cells. Cancer Treat Rep 70:275-278. 1986

\section{Notes}

Author affiliations: B. Jachez, R. Nordmann, Sandoz Pharma Lid., Preclinical Research, Basel, Switzerland.

F. Loor, Immunology Laboratory, Strasbourg 1 University, Ilkirch. France, and Preclinical Research, Sandoz Pharma Lid., Basel.

Correspondence to: Francis Loor, Ph.D., Immunology Laboratory, Strasbourg 1 University, BP 24, F. 67401 Illkirch. France.

The part of this work performed at the

Strasbourg 1 University was supported by grants from Sandoz Pharma Ltd., Basel.

Manuscript received April 16, 1992; revised November 23, 1992; accepted December 3, 1992.

\section{Growth Inhibition of Human Lymphoma Cell Lines by the Marine Products, Dolastatins 10 and 15}

\author{
Margaret Beckwith, Walter J. \\ Urba, Dan L. Longo*
}

Background: Dolastatins 10 and 15 are small peptides isolated from the marine sea hare Dolabella auricularia. In vitro studies of these peptides have demonstrated antimitotic and antiproliferative activity and growth inhibition in hematopoietic progenitor cells. Purpose: The purpose of our in vitro study was to determine the biological effects of these marine peptides on growth of human lymphoma cell lines and to investigate mechanisms by which the dolastatins may act. Methods: Cell lines DB, HT, RL, and SR were grown from the ascites or pleural effusion of four patients with lymphoma. The DB, HT, and RL cell lines are of B-cell origin, and the SR cell line appears to be a less differentiated lymphoid cell type. Cells from these lines were cultured in the presence of vincristine or dolastatin 10 or 15 . $\left[{ }^{3} \mathrm{H}\right]$ Thymidine-uptake assays were used to measure effects on DNA synthesis. Cell cycle analysis using propidium iodide was performed to measure drug-induced cellcycle arrest. DNA fragmentation was used as an assay for drug-induced apoptosis and was measured by agarose gel electrophoresis. Results: In the three B cell lines, dolastatin 10 was more effective than dolastatin 15. Values for concentrations required for inhibition of proliferation by $50 \%\left(\mathrm{IC}_{50}\right)$ were .00013 -.0013 $\mathrm{nM}$ for dolastatin 10 in each cell line; values for dolastatin 15 were approximately .13 $\mathrm{nM}$ in DB and HT cells and .0013-.013 $\mathrm{nM}$ in $R L$ cells. SR cells were more sensitive to dolastatin 15 than to dolastatin $10\left(\mathrm{IC}_{50}\right.$ $=.00013-.0013 \mathrm{n} M$ versus $.0013-.013$ $\mathrm{n} M$ ). Both dolastatins arrested more than $70 \%$ of cells in mitosis in all cell lines. This effect was reversed if the drug was removed by 4 hours, but by 8 hours of exposure, reversal was not possible. Both dolastatins 10 and 15 produced apoptosis in DB and HT cells but not in the other two cell lines. Conclusions: We have demonstrated that dolastatins 10 and 15 have a profound antiproliferative effect on four different human lymphoma cell lines and that the dolastatins are approximately 3-4 logarithms more effective as antiproliferative compounds, on a molar basis, than vincristine-a clinically useful, antiproliferative agent. These data support the hypothesis that apoptosis, as measured by DNA fragmentation, appears to be a cellspecific response and may not be directly related to the antimitotic effect of the dolostatins. Implications: Our results suggest that these compounds may be good candidates for development as antineoplastic agents. [J Nat] Cancer Inst 85:483-488, 1993]

In the past few years, there has been an intensive search for new antineoplastic agents derived from natural plant or animal sources. These efforts have revealed many potentially useful new compounds isolated from marine animals, including the bryostatins $(1-3)$, halichondrin $B$ and homohalichondrin $B$ (4), and the dolastatins (5-8). Among these natural compounds, the dolastatins appear to have the greatest therapeutic potential. The dolastatins are small peptides or depsipeptides isolated from the East Indian Ocean sea hare, Dolabella auricularia; at least 15 unique molecules have been identified (5-8).

In this report, we have analyzed the biological effect of two of these unusual peptides, dolastatins 10 and 15 $(5,6)$, on a panel of human lymphoma cell lines. Dolastatin 10 consists of four amino acid residues (dolavaline, valine, dolaisoleuine, and dolaproine) and has

"See "Notes" section following "References." 